\title{
A Compact MIMO Antenna with Inverted C-Shaped Ground Branches for Mobile Terminals
}

\author{
Zixian Yang, Hongchun Yang, and Haijuan Cui \\ School of Electronic Engineering, University of Electronic Science and Technology of China, Chengdu 610054, China \\ Correspondence should be addressed to Zixian Yang; 22225405@qq.com
}

Received 3 March 2016; Accepted 12 May 2016

Academic Editor: Miguel Ferrando Bataller

Copyright (C) 2016 Zixian Yang et al. This is an open access article distributed under the Creative Commons Attribution License, which permits unrestricted use, distribution, and reproduction in any medium, provided the original work is properly cited.

A compact printed MIMO antenna for mobile terminals is presented. With two planar antenna elements, the $-6 \mathrm{~dB}$ impedance bandwidth of $2.32 \mathrm{GHz}(1.48-3.8 \mathrm{GHz})$ is obtained, which covers GSM 1800/1900, UMTS, WLAN, Wimax, S-band, and most of LTE bands. Each antenna element with a small occupation of $15 \times 20 \mathrm{~mm}^{2}$ consists of a driven strip and a shorted strip. Two inverted C-shaped ground branches are introduced between two elements to improve the isolation. The simulated results are studied and the measured results show that high isolation of more than $18 \mathrm{~dB}$ at the entire operating band is achieved. Meanwhile, the impedance performance is also improved by adding the branches. Furthermore, the measured radiation performances and envelope correlation coefficient also demonstrate that the proposed antenna could be a good candidate for mobile terminals.

\section{Introduction}

In the last decade, the technologies of mobile wireless communication have been developing rapidly. From global system for mobile communication (GSM), universal mobile telecommunication system (UMTS) to long-term evolution (LTE), and wireless local area networks (WLAN), the data transfer rates reach a much higher level than ever before, so as the requirements of the mobile terminals. Multiple-input multiple-output (MIMO) technology with multiple antennas is a very effective way to guarantee data rate and increase system capacity [1]. However, the demand for compact size and numerous functions of mobile terminals brings great challenges of designing MIMO antenna with wide operating band covering multiple bands and low mutual coupling in a limited volume and it is still an open issue.

Various printed MIMO antennas designed for mobile terminals have been reported in recent years [2-9]. In [2], the proposed antenna resonates at multiple bands, which covers most $2 \mathrm{G}$ and $3 \mathrm{G}$ cellular frequency bands, some $4 \mathrm{G}$ LTE bands, WLAN, and Wimax bands. For two inverted L shaped ground branches and a rectangular slot with one circular end, a good isolation of more than $15 \mathrm{~dB}$ is achieved. But the size of the antenna is not compact enough for a mobile phone and the structure is complicated. The antennas in $[3,4]$ both have the operating bandwidth covering GSM850/900/1800/1900, UMTS, and a few LTE bands. However, in [3], a simple protruded ground makes the coupling only less than $-10 \mathrm{~dB}$; in [4], the isolation is more than $12 \mathrm{~dB}$ with a T-shaped ground stub as decoupling structure but still needs to be improved. In [5, 6], the design of [5] using a decoupling network of two sections of a transmission line between two radiators has a very high isolation of $23 \mathrm{~dB}$. But the antenna can only work at LTE 13; the antenna in [6] operates in LTE 7 and $2.0-2.8 \mathrm{GHz}$, but the isolation is poor. For the antennas in [7-9], four-antenna MIMO system in [7] has small size of radiator and good isolation but only works at WLAN. Reference [8] also used a T-shaped ground stub to increase isolation, but the mutual coupling still reaches $-11 \mathrm{~dB}$ at the peak. In [9], a simple meandered monopole MIMO antenna is presented. With the dual decoupling structures consisting of ground slots and inverted L ground branches, the isolation achieved is better than $15 \mathrm{~dB}$. Nonetheless, the two antenna elements with the ground branches are placed at the top and bottom edges of the substrate, respectively, which occupy twice area as the antennas in other references. And the operating bandwidth is $1.7-2.9 \mathrm{GHz}$, which needs to be improved as well. 


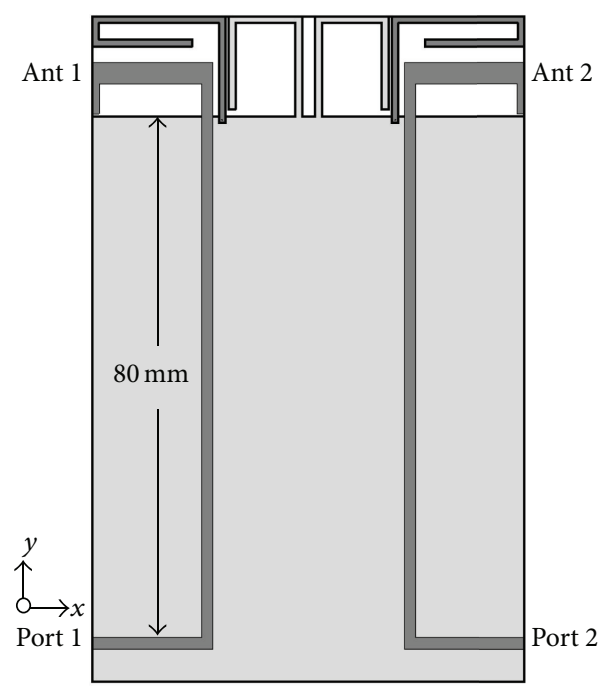

(a)

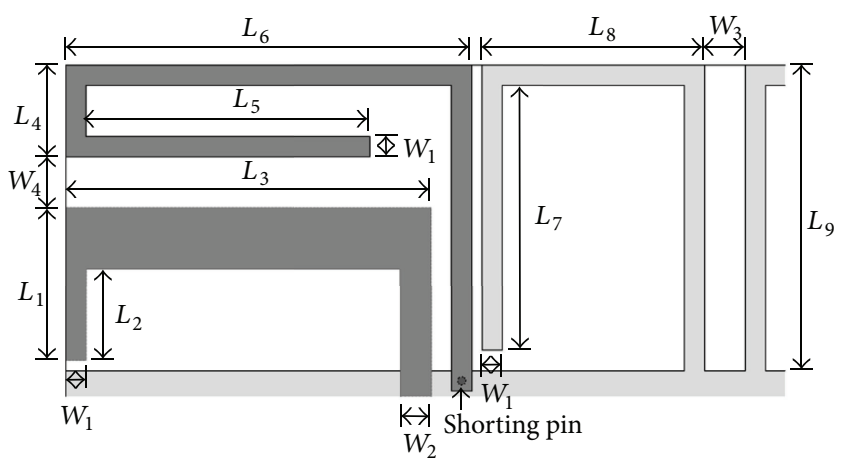

(b)

FIGURE 1: Geometry of the proposed antenna: (a) overall view and (b) detailed view.

In this paper, a wideband printed MIMO antenna with high isolation for mobile terminals is proposed. This antenna has two radiating elements with a compact size of $15 \times$ $20 \mathrm{~mm}^{2}$ for each. Two inverted C-shaped ground branches as decoupling structure are located between the antenna elements to improve isolation. The antenna is simulated, fabricated, and measured. The measured $-6 \mathrm{~dB}$ impedance bandwidth is $2.32 \mathrm{GHz}$ from 1.48 to $3.8 \mathrm{GHz}$, which covers GSM1800/1900, UMTS, most of LTE bands, WLAN, Wimax, and S-band satellite communication service. At the same time, high isolation of more than $18 \mathrm{~dB}$ at the entire band is achieved. As compared to [9], the proposed antenna has much wider bandwidths of impedance and better isolation with less occupied area.

\section{Antenna Design}

Figure 1(a) shows the geometry of the proposed antenna. The substrate is FR4, with a dielectric constant of 4.4, a loss tangent of 0.02 , and a thickness of $0.8 \mathrm{~mm}$. The overall size of the antenna is $100 \times 65 \mathrm{~mm}^{2}$. The two printed planar antenna elements with size of $15 \times 20 \mathrm{~mm}^{2}$, fed by $50 \Omega$ impedance microstrip feedline, are placed symmetrically at the top layer. Each antenna element has a driven strip with a dimension of $W_{1}, W_{2}, L_{1}, L_{2}$, and $L_{3}$ and a shorted strip with a dimension of $W_{1}, L_{4}, L_{5}$, and $L_{6}$. Two inverted C-shaped branches on the ground plane are located between the two elements, which have a dimension of $W_{1}, L_{7}$, and $L_{8}$ and the gap of the two branches is denoted by $W_{3}$. The detailed view of the antenna element is shown in Figure 1(b).

To study the effects of the inverted C-shaped ground branches, simulations of $S$ parameters in different situations are carried out using CST Microwave Studio, based on
Finite Difference Time Domain (FDTD), and the results are presented in Figure 2. As it is shown in Figure 2(a), without the ground branches, the values of $S_{21}$ are greater than $-15 \mathrm{~dB}$ from 1.3 to $2.0 \mathrm{GHz}$, especially around $1.5 \mathrm{GHz}$, and almost reach $-5 \mathrm{~dB}$. However, the isolation is greatly enhanced by introducing the inverted $\mathrm{C}$-shaped ground branches between the antenna elements. As a result, the values of $S_{21}$ are less than $-16 \mathrm{~dB}$ at all frequencies. Meanwhile, the impedance performance is also improved by the branches from 2.5 to 3.3 GHz, as it is shown in Figure 2(b). Figure 3 shows a further study on the surface current distribution with and without the ground branches at $1.6 \mathrm{GHz}$ when port 1 is excited. In Figure 3(a), without the ground branches, a large number of surface currents are coupled to port 2, leading to the low isolation between antenna elements. Contrarily, with the inverted C-shaped ground branches in Figure 3(b), most current flow from port 1 to port 2 is blocked and the mutual coupling between the antenna elements is obviously reduced.

The radiating mechanism of the proposed antenna is also studied in Figure 4, which shows the surface current distribution at different frequencies when port 1 is excited. In Figure 4(a), the antenna is radiating at $1.6 \mathrm{GHz}$ from the shorted strip and part of the driven strip. The total length of the two parts is around $45.5 \mathrm{~mm}$, which is about $0.5 \lambda$, where $\lambda$ is the guided wavelength at $1.6 \mathrm{GHz}$ and it can be calculated by

$$
\lambda=\frac{c}{f_{c} \cdot \sqrt{\varepsilon_{\mathrm{eff}}}}
$$

where $c$ is the speed of light, $f_{c}$ is the resonant frequency, and $\varepsilon_{\text {eff }}$ is the effective permittivity of the substrate, which is 3.32 in this case. At $2.3 \mathrm{GHz}$, the resonance is manly generated by the driven strip and a few parts of shorted strip with the length 


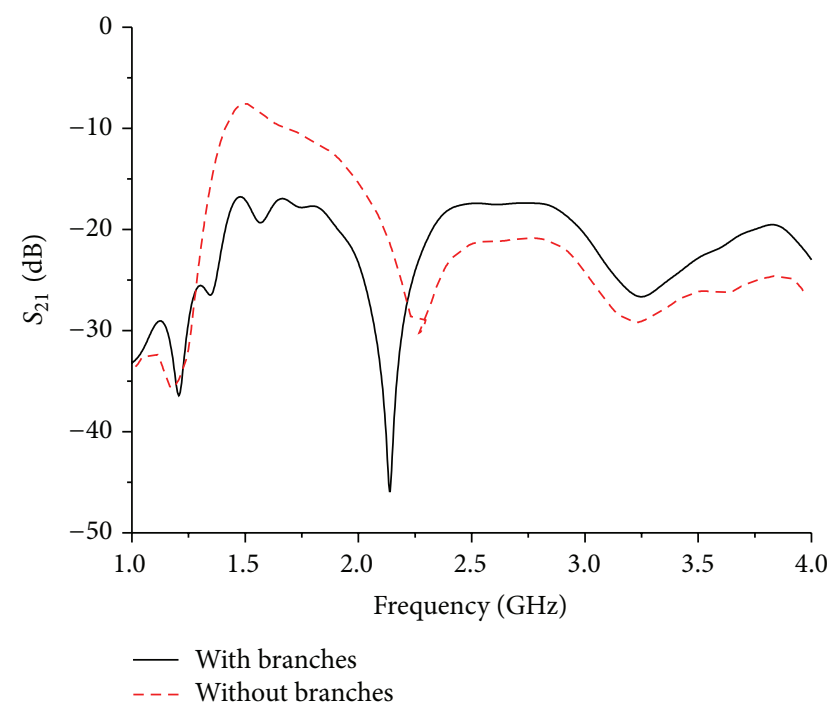

(a)

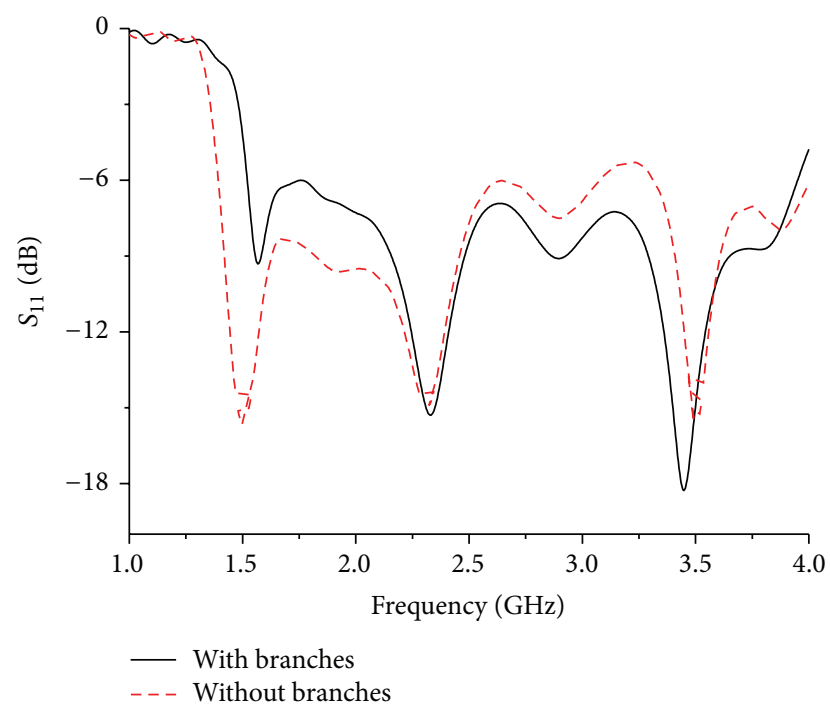

(b)

FIGURE 2: Simulated results with/without ground branches: (a) $S_{21}$; (b) $S_{11}$.

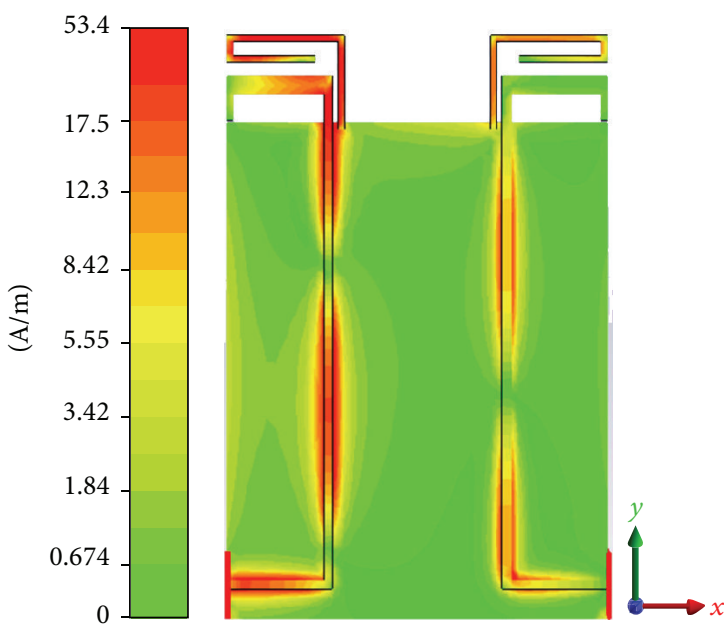

(a)

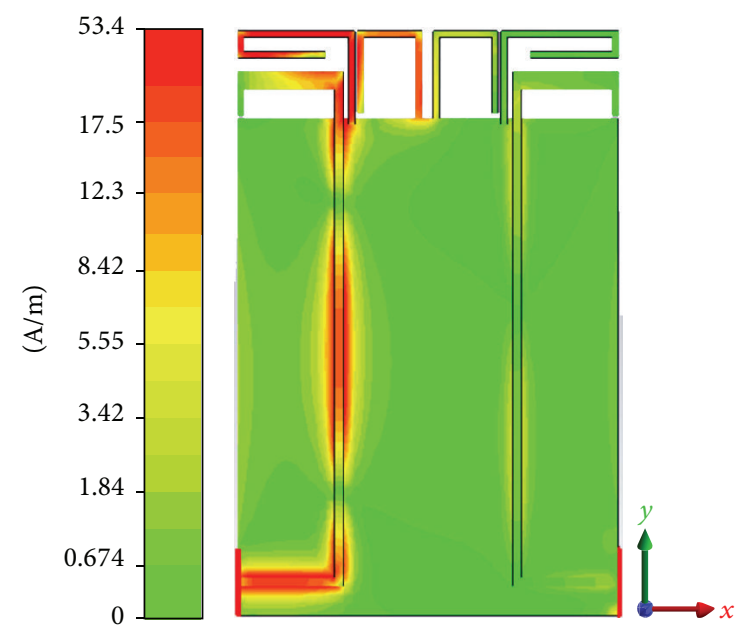

(b)

FIGURE 3: Surface current distribution at 1.6 GHz: (a) without ground branches; (b) with ground branches.

of $0.5 \lambda$, as it is seen in Figure 4(b). Figure 4(c) shows that the part of the antenna that is radiating at $3.4 \mathrm{GHz}$ is the shorted strip, which has the length of about $30 \mathrm{~mm}$, nearly $0.5 \lambda$. It is also shown that the inverted C-shaped ground branches affect the upper frequency band much less than the lower frequency band.

\section{Results and Discussion}

Figure 5 shows the fabricated antenna and the final optimized dimensions are as follows: $W_{1}=1 \mathrm{~mm}, W_{2}=1.5 \mathrm{~mm}, W_{3}=$ $2 \mathrm{~mm}, W_{4}=2.5 \mathrm{~mm}, L_{1}=7.5 \mathrm{~mm}, L_{2}=4.5 \mathrm{~mm}, L_{3}=18 \mathrm{~mm}$, $L_{4}=3.5 \mathrm{~mm}, L_{5}=14 \mathrm{~mm}, L_{6}=20 \mathrm{~mm}, L_{7}=13 \mathrm{~mm}, L_{8}=$ $11 \mathrm{~mm}$, and $L_{9}=15 \mathrm{~mm}$.
Figure 6 shows the simulated versus measured results of $S$ parameters. As the two antenna elements are symmetrical, only $S_{11} / S_{22}$ and $S_{21} / S_{12}$ are shown. The measured bandwidth is $2.32 \mathrm{GHz}$ from 1.48 to $3.8 \mathrm{GHz}$ as a return loss of $6 \mathrm{~dB}$. So that the proposed antenna is capable of covering GSM1800/1900 (1.71-1.99 GHz), UMTS (1.92$2.17 \mathrm{GHz})$, WLAN $(2.4-2.48 \mathrm{GHz})$, Wimax $(3.4-3.6 \mathrm{GHz})$, S-band (1.55-3.4 GHz), and LTE bands 1-4, 9-11, and 2140 [10]. Good agreement between simulated and measured results is observed except a slight shift, probably caused by manufacturing tolerance. The measured mutual coupling is less than $-18 \mathrm{~dB}$ at the entire band. Compared to the reference antenna [9], the bandwidth is nearly as twice and the isolation is $3 \mathrm{~dB}$ more, with half occupation of the radiators and decoupling structures. 


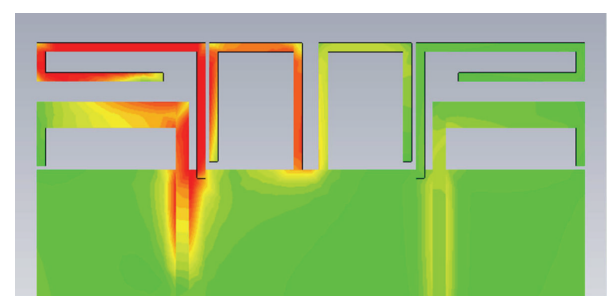

(a)

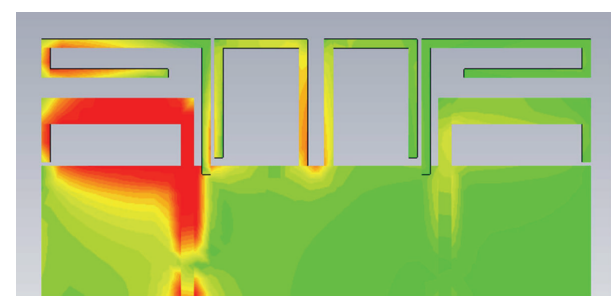

(b)

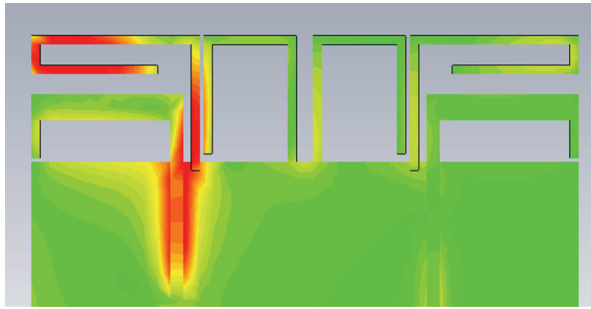

(c)

FIGURE 4: Surface current distribution of the proposed antenna at (a) $1.6 \mathrm{GHz}$; (b) $2.3 \mathrm{GHz}$; (c) $3.4 \mathrm{GHz}$.

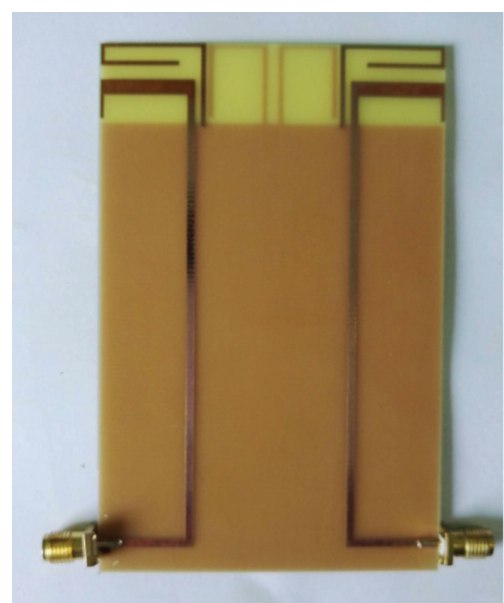

(a)

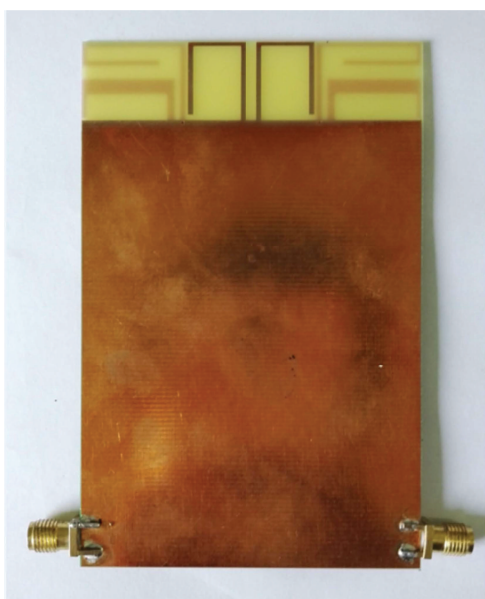

(b)

Figure 5: Photo of the fabricated antenna: (a) front view; (b) back view.

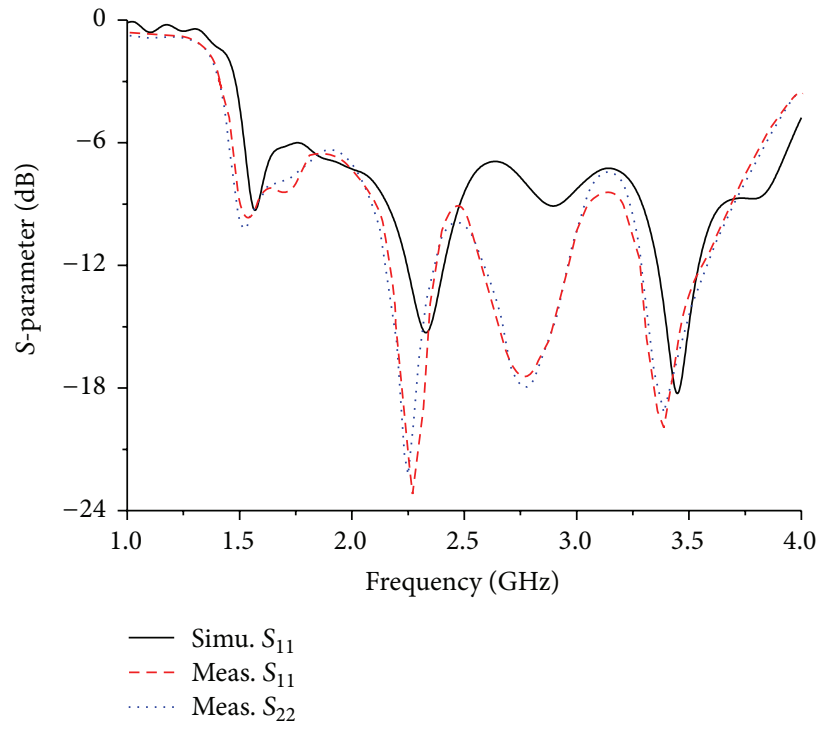

(a)

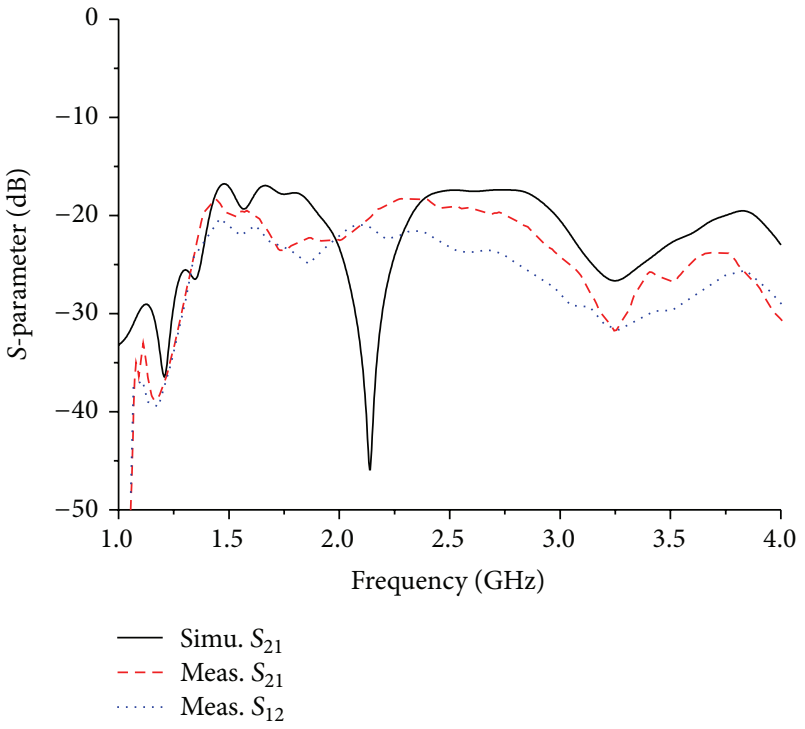

(b)

FIGURE 6: Simulated and measured $S$ parameters of the proposed antenna: (a) $S_{11}$; (b) $S_{21}$. 


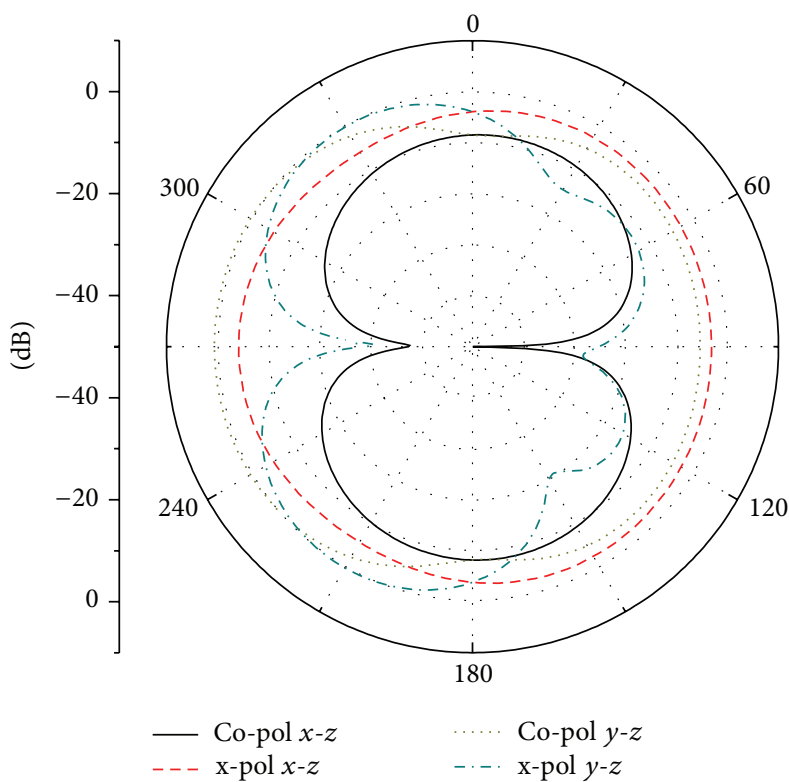

(a)

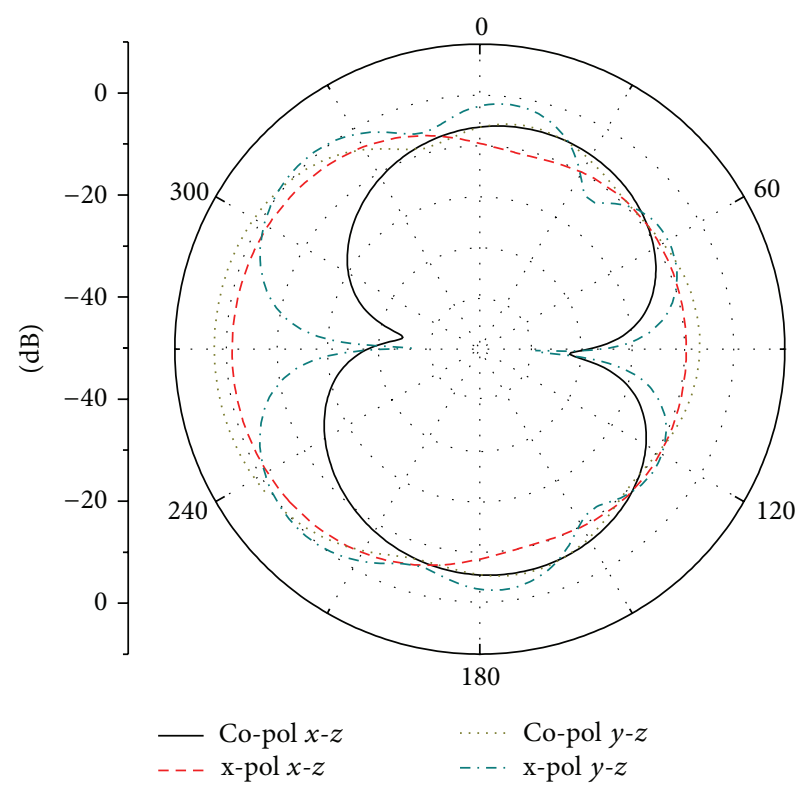

(b)

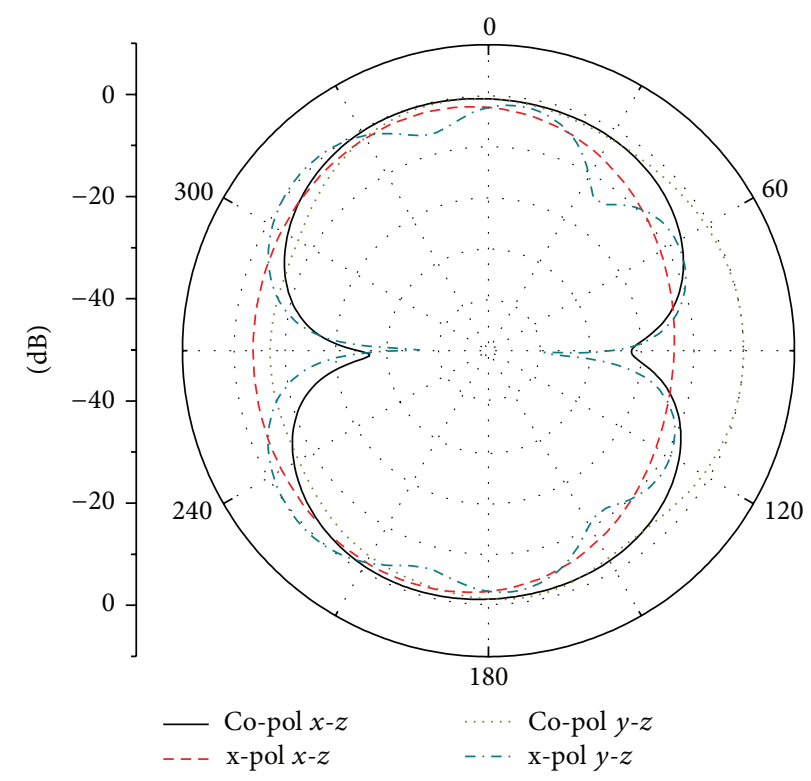

(c)

FIGURE 7: Measured patterns of the proposed antenna at (a) $1.5 \mathrm{GHz}$; (b) $2.4 \mathrm{GHz}$; (c) $3.5 \mathrm{GHz}$.

Figure 7 shows the measured patterns of the proposed antenna when port 1 is excited and port 2 is terminated with a $50 \Omega$ load. The patterns on the $x-z(H)$ plane and $y-z$ (E) plane at $1.5 \mathrm{GHz}, 2.4 \mathrm{GHz}$, and $3.5 \mathrm{GHz}$ are presented in Figures 7(a), 7(b), and 7(c), respectively. Good performance and quasi omnidirection in $H$ plane are obtained.

Figure 8 shows the measured peak gains and radiation efficiency of the antenna. The peak gains are from 1.5 to $3.4 \mathrm{~dB}$ and the radiation efficiency is above $60 \%$ at the operating bands. It also can be seen that, compared to the frequencies with lower return loss value, the gains and efficiency are more at the frequencies where the impedance of the antenna is better.
To further describe the diversity performance of the proposed antenna, the ECCs (envelope correlation coefficient) are calculated by [11]

$$
\rho_{e}=\frac{\left|S_{11}^{*} S_{12}+S_{21}^{*} S_{22}\right|^{2}}{\left(1-\left|S_{11}\right|^{2}-\left|S_{21}\right|^{2}\right)\left(1-\left|S_{22}\right|^{2}-\left|S_{12}\right|^{2}\right)} .
$$

Figure 9 shows the simulated and measured ECCs. As it is seen, the simulated ECCs are below 0.012 over the whole band, while the measured results are below 0.01 . It is promised that the proposed antenna can be a good candidate for mobile terminals. 


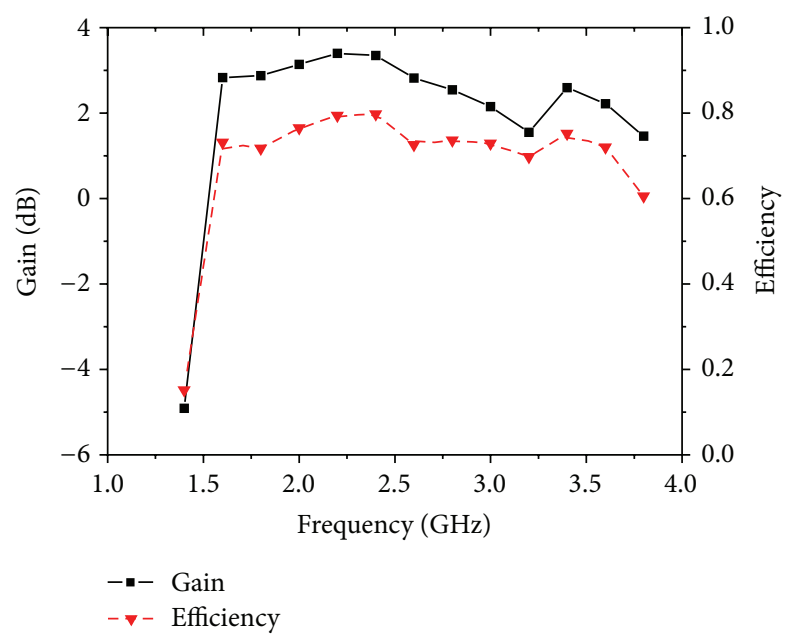

FIGURE 8: Measured gain and efficiency of the proposed antenna.

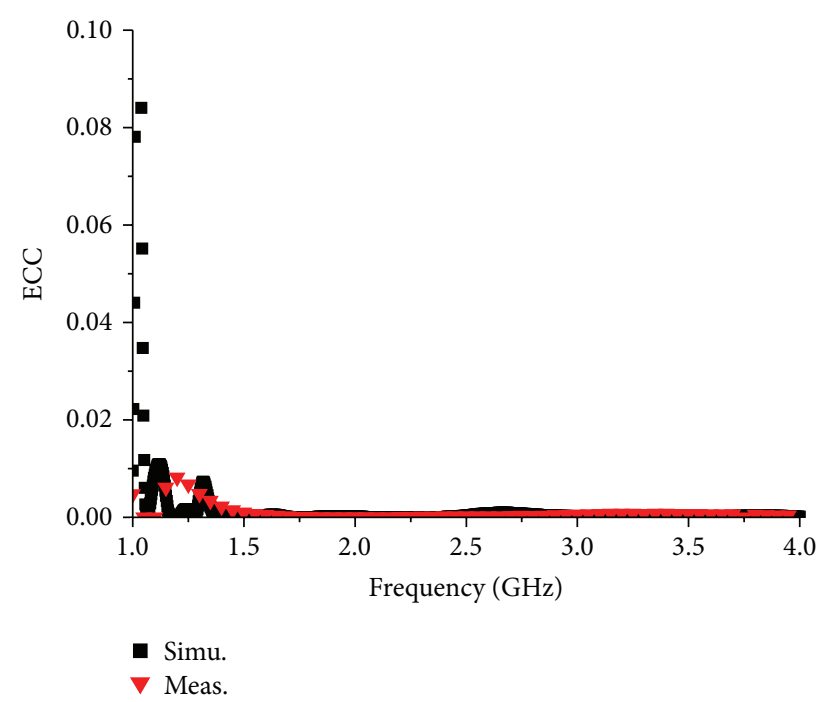

FIGURE 9: Simulated and measured ECCs of the proposed antenna.

\section{Conclusion}

This paper describes a wideband compact MIMO antenna with high isolation for mobile terminal applications. Each of the two antenna elements is composed of a driven strip and a shorted strip to obtain the operating bandwidth from 1.48 to $3.8 \mathrm{GHz}$, which covers GSM1800/1900, UMTS, WLAN, Wimax, S-band, and most of LTE bands. Two inverted Cshaped ground branches are introduced to decrease the mutual coupling and high isolation of more than $18 \mathrm{~dB}$ across the whole band is achieved. The structure of the proposed antenna is simple and easy to optimize. Good radiation performances are also obtained and the envelope correlation coefficient is less than 0.01 , making it would be suitable for the MIMO system of mobile terminals.

\section{Competing Interests}

The authors declare that there are no competing interests regarding the publication of this paper.

\section{References}

[1] X. M. Ling and R. L. Li, "A novel dual-band MIMO antenna array with low mutual coupling for portable wireless devices," IEEE Antennas and Wireless Propagation Letters, vol. 10, pp. 1039-1042, 2011.

[2] S. Shoaib, I. Shoaib, N. Shoaib, X. Chen, and C. G. Parini, "Design and performance study of a dual-element multiband printed monopole antenna array for MIMO terminals," IEEE Antennas and Wireless Propagation Letters, vol. 13, pp. 329-332, 2014.

[3] Y. Wang, J. Yang, S. Hao, and X. Zhang, "Wideband dualelement antenna array for mimo mobile phone applications," International Journal of Antennas and Propagation, vol. 2015, Article ID 434082, 7 pages, 2015.

[4] Y.-L. Ban, S. Yang, Z. Chen, K. Kang, and J. L.-W. Li, “Decoupled planar WWAN antennas with T-shaped protruded ground for smartphone applications," IEEE Antennas and Wireless Propagation Letters, vol. 13, pp. 483-486, 2014.

[5] J. Baek and J. Choi, "The design of a LTE/MIMO antenna with high isolation using a decoupling network," Microwave and Optical Technology Letters, vol. 56, no. 9, pp. 2187-2191, 2014.

[6] X. Zhao and J. Choi, "Wideband loop antenna using distributed elements for 4G MIMO mobile application," Microwave and Optical Technology Letters, vol. 56, no. 3, pp. 577-581, 2014.

[7] H. Huang, Y. Liu, and S.-X. Gong, "Four antenna MIMO system with compact radiator for mobile terminals," Microwave and Optical Technology Letters, vol. 57, no. 6, pp. 1281-1286, 2015.

[8] C. Yang, Y. Yao, J. Yu, and X. Chen, "Novel compact multiband MIMO antenna for mobile terminal," International Journal of Antennas and Propagation, vol. 2012, Article ID 691681, 9 pages, 2012.

[9] S. Shoaib, I. Shoaib, N. Shoaib, X. Chen, and C. G. Parini, "MIMO antennas for mobile handsets," IEEE Antennas and Wireless Propagation Letters, vol. 14, pp. 799-802, 2015.

[10] Radio Electronics, Resources, and Analysis for Electronic Engineers, "LTE frequency bands and spectrum allocations," http://www.radio-electronics.com/info/cellulartelecomms/ltelong-term-evolution/lte-frequency-spectrum.php.

[11] S. Blanch, J. Romeu, and I. Corbella, "Exact representation of antenna system diversity performance from input parameter description," Electronics Letters, vol. 39, no. 9, pp. 705-707, 2003. 


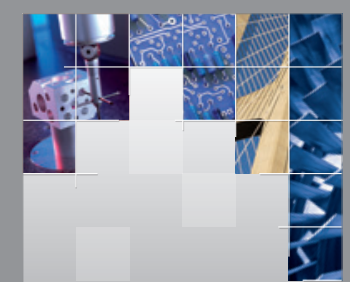

\section{Enfincering}
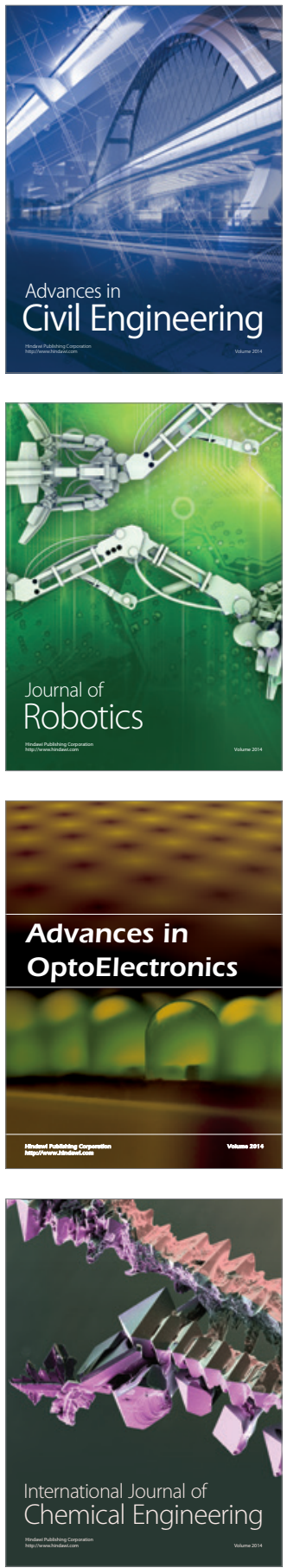

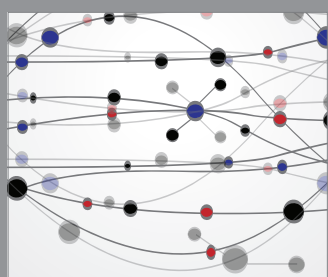

The Scientific World Journal

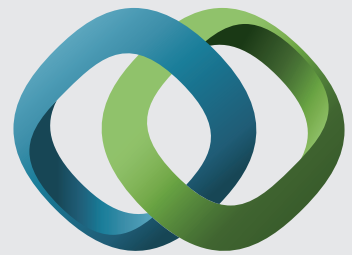

\section{Hindawi}

Submit your manuscripts at

http://www.hindawi.com
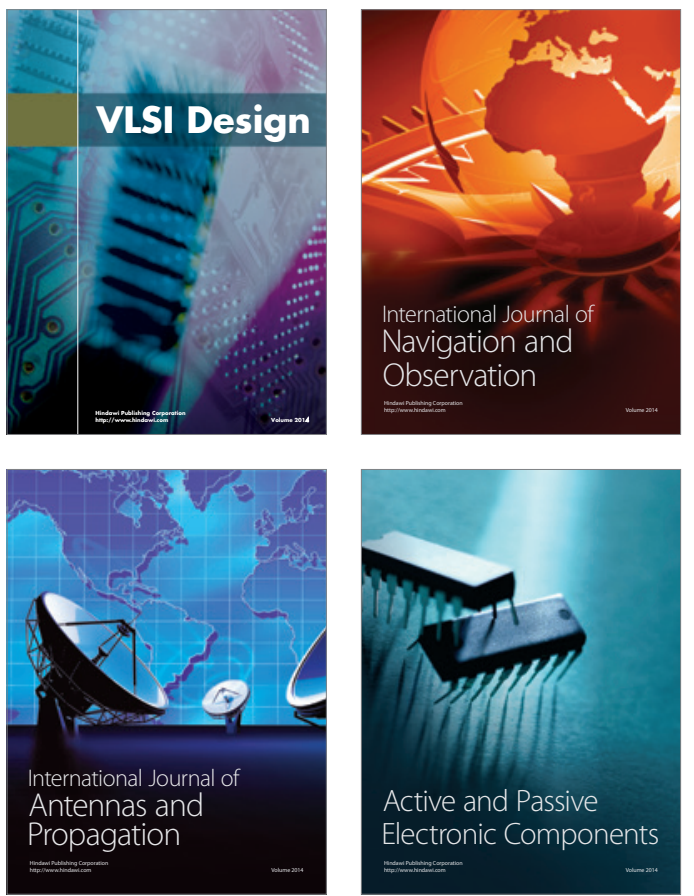
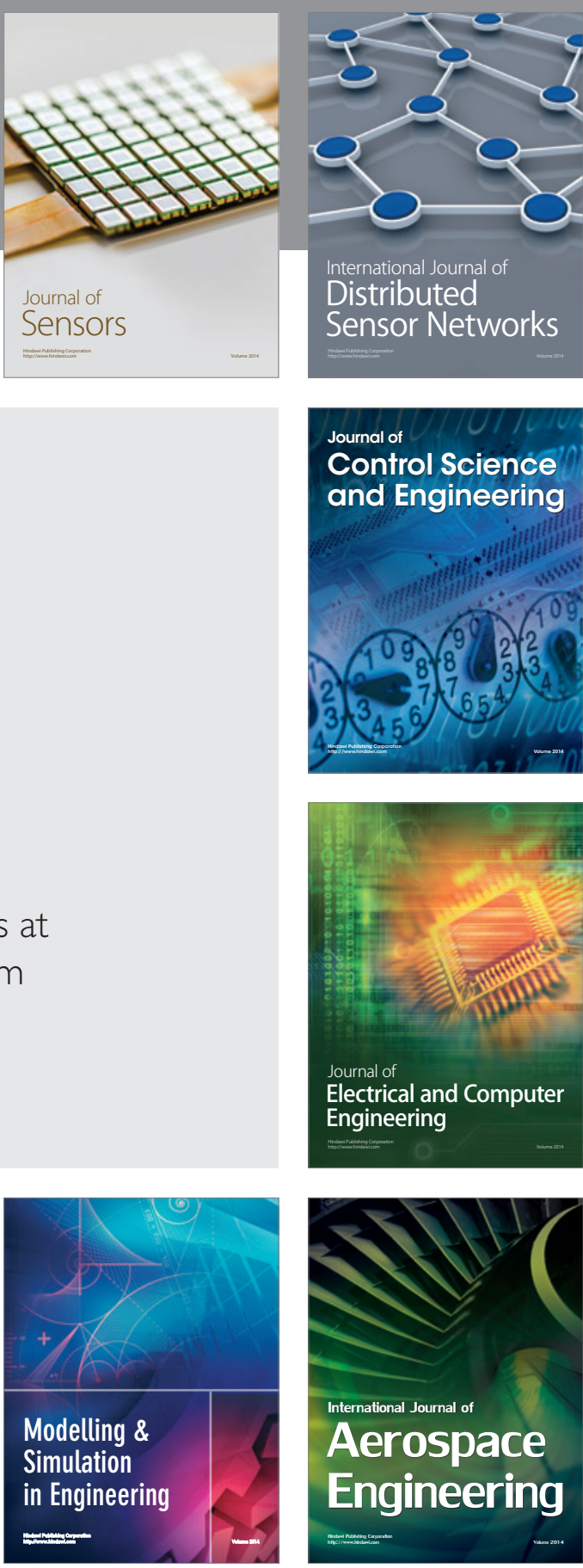

International Journal of

Distributed

Sensor Networks

Journal of

Control Science

and Engineering
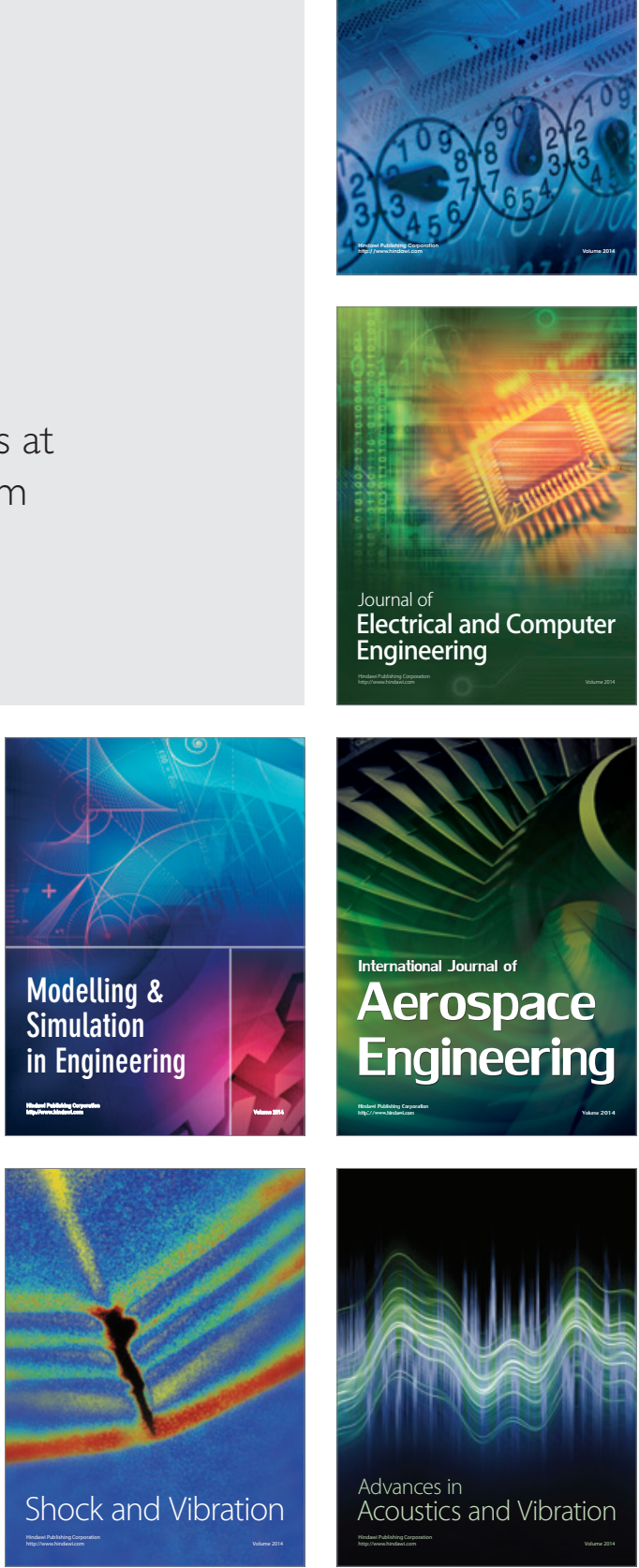